\title{
English-Arabic Contrastive Analysis Redefinition of Goals
}

\author{
May F. Al-Shaikhli \\ Department of Translation, Isra University, Amman, Jordan \\ Email: may7070may@yahoo.com \\ Ibrahim Abdel-Latif Shalabi \\ Department of English, Isra University, Amman, Jordan \\ Email: shalabi61@yahoo.com
}

\begin{abstract}
The purpose of this paper is to assess the current status of English-Arabic Contrastive Analysis (CA) in Iraqi universities \& to suggest some redefinitions of the goals of this analysis accordingly. A sample of 25 theses that have been randomly chosen has been investigated and chronologically appended. The historical background will have a bird's eye view on the various phases $\mathrm{CA}$ in general has undergone so far. One of the limitations is consulting English references only, admitting that Arab scholars did have their own contribution as well.
\end{abstract}

Index Terms - comparative philology, pedagogic, structuralism, universal CA, bilingual, multilingual, linguistics, syntax, phonology, morphology, semantics

\section{HISTORICAL BACKGROUND}

With respect to purpose, $\mathrm{CA}$ in general is undergoing now its third phase.

As the situation in the mother field, linguistics itself, is, the major trends in CA swing in their conflicts and developments from focus on similarities to focus on differences between languages. So, to differentiate between these three phases is to identify the aims and techniques of each period.

\section{A. Comparative Philology}

This is the first phase of linguistics itself. It started in 1786, when the Englishman William Jones discovered the great structural similarities between Sanskrit, Greek, Latin, and Germanic \& Celtic:

"The Sanskrit language ... is of a wonderful structure; more perfect than the Greek, more copious than the Latin, and more exquisitely refined than either, yet bearing to both of them a stronger affinity, both in the roots of verbs \& in the forms of grammar, than could possibly have bean produced by accident ... no philologer could examine them all three, without believing them to have sprung from some common source, which, perhaps, no longer exists: there is a similar reason . . . for supposing that both the Gothic \& the Celtic . . . have the same origin with the Sanskrit; and the old Persian might be added the same family". (Simpson, 1979, p. 20).

An example of this correspondence is the following table:

\begin{tabular}{|l|l|l|l|}
\hline English & Latin & Greek & Sanskrit \\
\hline \hline Mother & Matrem & Mètèra & Matáram \\
\hline Two & Duo & Dúo & Dvaù \\
\hline Mouse & Mus & Mûs & Müs \\
\hline Three & tres & Trêis & Tráyas \\
\hline
\end{tabular}

(Ibid)

It is worth noticing that Jones did not expand his list to include such languages as Arabic \& Chinese although he was familiar with both.

However, Jones's discovery of this similarity fired the imagination of all European scholars who followed his example, and with this started a new era in the study of language-linguistics in its first form: comparative philology, which practically lasted till the appearance of Saussure's book in 1916 \& which brought about genuine discoveries in the field of language genealogy.

To related languages to each other and to discover their language families, scholars of that period developed a great number of principles and rules to guide them. Rask, for example, stressed in 1814 dependence on inflectional endings and sound correspondences rather than vocabulary similarities, which might be due to mere borrowing. Grimm as well established in 1822 his sound-shift law in which he showed how certain consonants have shifted from their original values in Germanic languages but not in Latin. (Ibid, p. 21). 
In comparing languages, they extended their painstaking efforts to some dead languages, which they tried to reconstruct on the bases of certain principles and procedures.

The majority principle, for instance, may be stated as follows:

"If, in a cognate set, three forms begin with a [p] sound and one form begins with a [b] sound, then our best guess is that the majority have retained the original sound (i, e.[p]), and the minority has changed a little through time". (Yule, 1988, p. 170).

Later on, the Danish scholar Karl Verner publicized his law in 1875 in which he tried to modify what Grimm had said about sound-change:

"Verner assumed that Sanskrit had preserved the place of the earlier Indo-European word-accent and that the Germanic 'sound-shift' had taken place before the accent was shifted to word-initial position in some prehistoric period of Germanic". (Lyons, 1968, p. 29).

Verner's Law in fact paved the way for the appearance of a small group of scholars nicknamed 'Young Grammarians' in the last quarter of the $19^{\text {th }}$ century. They held that language change is both regular and haphazard. It is haphazard in the sense that it is not possible to predict its occurrence nor to envisage its direction. It is regular as it is normally comprehensive and easily stateable:

". . . if, in any word of a given dialect, one sound changes into another, the change will also affect all other occurrences of the same sound in similar phonetic surroundings". (Aitchison, 1987, p. 30).

It is during this period that special attention was paid to language typology ${ }^{\bullet}$ through classifying languages either morphologically or syntactically.

From the morphological point of view, languages were classified into isolating (Chinese), agglutinating (Turkish) and fissional (Latin) ones:

"The number of morphemes per word varies from language to language - so does the way in which morphemes are combined within a word". (Ibid, p. 149).

Needless to say, a language is isolating if its words usually consist of one morpheme only, agglutinating if its words divide into morphemes easily and fissional if its morphemes are not easily divisible.

Syntactically, languages are classified into six groups:

\begin{tabular}{|l|l|}
\hline SVO & English \\
\hline \hline SOV & Japanese \\
\hline VSO & Arabic** \\
\hline VOS & Malagasy \\
\hline OSV & Apurina \\
\hline OVS & Hixkaryana \\
\hline
\end{tabular}

Although some people are still interested in tracing language origins in one way or another, comparative philology as a trend received a deadly blow through the appearance of Saussure's book, in 1916, which criticized this trend for restricting itself to diachronic studies only.

What is odd about this phase is that it is for some linguistics a pre-linguistic ear. Simpson, for example, links the actual evolvement of linguistics to Saussure's book. (Simpson, 1979, p. 35).

Lyons and Aitchison, on the other hand, attest the majority's view that 1786 IS the birth date of linguistics (Lyons, 1968, p. 33). (Aitchison, 1987, p. 30).

However, what is important for the present paper is that comparative philology preceded contrastive linguistics but it is NOT part of it.

\section{B. Pedagogic $C A$}

The retreat of comparative philology in front of Saussure's structuralism brought about a period of about thirty years during which linguistic comparison was virtually absent. Europe then was too fascinated by Saussure's dichotomies and focus on linguistic interrelations to compare languages. America was too busy as well with following up the American Indian languages that were dying away quite rapidly to compare. Moreover, the appearance of Boomfieldian linguistics in the thirties, also called structuralism but for another reason was not in favor of language comparison, as Bloomfield exaggerated language differences and denied the possibility of setting up any classification system that would apply to all languages.

Strangely enough, two prominent students of Bloomfield's, Charles Fries and Robert Lado developed in the forties the technique of CA in their painstaking search for better materials and methods of foreign language teaching:

"The most efficient materials are those that are based upon a scientific description of the language to be learned, carefully compared with a parallel description of the native language of the learner". (Fries, 1945, p. 9).

\footnotetext{
- Though both CA and typology are synchronic in their approaches, they differ in that typology restricts itself to a certain feature shared by a number of languages. Whereas CA focuses on different feater in two or more languages.

- Arabic is sometimes an SVO language as well.
} 
To improve these materials and methods, Fries and Lado, and many others, resorted both to linguistics and to the psychology for consultation.

Linguistics supplied them with Bloomfieldian Structuralism which has been characterized by formal descriptiveness and detailed categorization:

"[Structuralism] emphasized the importance of detailed 'scientific description' of languages based on a description of the different categories that make up the patterns of a language. These categories were defined in formal terms and they were established inductively". (Ellis, 1985, p. 25).

Psychology, on the other hand, supplied CA with behaviorism, the true ally of structuralism. Behaviousism interpreted the activity of second language learning as a process of acquiring new habits. A habit for him is constituted by linking a certain response with a certain stimulus. Later on, Skinner (1957), however, minimized the role of the stimulus \& held that it was the behavior that followed a response, which reinforced it. (Ibid, p. 21).

In its rejection of any mental aspect of language learning, behaviorism introduced the notion of interference, which causes errors when it is negative and results in facilitation when positive.

Pedagogic CA may then be defined as the comparison of two or more languages for the purpose of locating areas of (dis) similarities. It is built on the principle that similar items are easier in foreign language learning than dissimilar ones.

The problem with the CA hypothesis is that it has two extremities: a strong form and a weak one.

An illustration of its strong form is Lee's note:

"The prime cause, or even the sole cause, of difficulty and error in foreign language learning is interference coming from the learner's native language". (Lee quoted by Ellis, 1985, p. 23).

The weak form simply states that CA can simply specify which errors are attributable to interference. An extreme example of this form is Dulay \& Burt's claim that "only 3 per cent of all learner's errors were the result of interference". (Ibid ,p. 28). Other researchers raised the percentage considerably. Mukattash, for example, assigned 23\% of the errors of his English-learning Arab students to interference. (Ibid,p. 29).

The place of CA was drastically shaken when Chomsky severely attacked Skinner's behaviouristic interpretation of language acquisition as he nullified such notions as stimulus, response, analogy, imitation and reinforcement, rejecting them as irrelevant to the activity of language acquisition.

A further attack on pedagogic CA was that it may predict errors that may not really occur and it may skip errors, which may take place. By employing what Schachter called in 1974 'avoidance strategy' a learner may avoid producing a difficult item "by resorting to paraphrase, or to some near-equivalent". (James, 1980, p. 22). In a well-known experiment Schachter found out that in learning English relative clauses, the Chinese learners, whose language does not contain English-like relative clauses, make fewer errors than Arab learners, whose language resembles English in relative clause structures. Investigating the actual responses, she observed that her Chinese learners did not use this structure as much as the Arab ones did. They simply avoided suing it. (Ellis, 1985 ,p. 33).

Other negative remarks were the actual lack of theoretical bases of comparison and the absence of all pragmatic aspects in that comparison.

For all these reasons and others, the great expectations, which many scholars hanged on pedagogic CA, were gradually dashed, and, without disappearing completely, it retreated considerably in its popularity and gave way to the third phase to appear and to accompany it in the last quarter of the twentieth century. As for educators, syllabus designers and practical teachers, they, instead, renewed their interest in the classic technique of error analysis and in its more valid and more realistic promises.

\section{Universal $C A$}

This term has been coined in this essay to refer to the third phase of CA, in which CA devoted itself to enriching and verifying the major principles and parameters of universal grammar. A major task of grammarians today is to split the details of the grammar into core grammar, i.e., what belongs to universal grammar, and peripheral grammar, i.e., what belongs to that specific grammar:

"We want to know which properties of English are language specific . . . and which are universal". (Haegeman and Gueron, 1999 ,p. 582).

In order to split these two types of property, one may make grammar as explicit as possible, which will enable one to see which, phonological, morphological, syntactic and semantic features are common and which are not.

Among the major hypotheses that transformational grammar has introduced in this respect is that mere exposure to a language is not enough for acquiring it. This triggering experience does not enable the learner of English, for example, to figure out when the declarative complementizer 'that' is optionally or obligatorily overt, as in these two sentences:

He said that he was ready

That he arrived alone surprised everybody

The problem with this exposure is that it does not provide the learner with the negative experience required for such judgments.

\footnotetext{
- This school which was expounded by John Watson (1878-1958) flourished in the second quarter of the twentieth century. It stresses the role of environment in learning and excludes from its domain all sorts of behavior that may not be objectively observed.
} 
Something greater that this exposure, therefore, lies behind the linguistic knowledge . . It is universal grammar, that innate cognitive capacity, which enables the learner to know his language infinitely through that finite exposure, that is, to judge correctly whether a certain sentence is grammatical or not even without necessarily being previously exposed to it. This universal grammar expounds itself through certain principles and parameters.

Principles are those predetermined rules. To quote Haegeman and Gue'ron again:

"they are given at birth; they are part of the cognitive capacity enabling us to acquire language and they themselves do not have to be acquired". (Ibid ,p. 284).

A basic principle, for example, is that the selectional properties of the verb determine the composition of a sentence.

A second principle is the Empty Category Principle, which requires the identification of empty categories.

A third example is the principle of Full Interpretation, which requires that each symbol in the syntactic representation of a sentence by integrated into its total interpretation. Accordingly, the omission of the complementizer 'that' in the above mentioned sentence:

He arrived alone surprised everybody is not possible, as this empty category remains unidentifiable, which renders it uninterruptible.

The important thing about these principles is that they are never in their final shapes:

"These hypothetical principles of UG are open to further testing against data from other languages which may either confirm their universal character, possibly in a modified form, or reveal their language - specific character. They may also force their rejection altogether". (Ouhalla, 1979, p. 297).

Parameters, on the other hand, are limited choices, which vary cross linguistically.

"A parameter is understood to be a restricted set of options / values associated with a given principle or category. Choice of one option / value yields a given pattern, and choice of a different option / value yields a different pattern". (Ibid,p.298).

One example is the object shift parameter, which assumes that SVO and SOV languages have basically the same word order: both are SVO order. Some of them, like English, have stuck to it; others, like German, have chosen to move the object leftward across the verb.

A second example of parameterization is the strength or weakness of verbal inflection. Weak agreement, as in English, does not enable the verb to move leftward to agreement. Thus, it is possible to say:

John always eats chocolate

But it is ungrammatical to say:

John eats always chocolate

In French, however, where agreement is strong, it is said the other way around:

Jean mange toujours du chocolate (Haegeman and Gue'ron, 1999, p. 587).

These are just sporadic examples of what is going on nowadays in generative linguistics. To verify these principles and parameters, they ought to be checked along as many examples as possible. To achieve this verification, CA has stepped forward in its new robe. Since the seventies, it has assumed a more theoretical responsibility without completely deserting its pedagogic task. Languages began to be compare just to see to what extent the current principles and parameters are comprehensive in their application. As a matter of fact, the mere subjecting of some well-known languages to this verification has indirectly shed light on their secrets and solved lots of their learning difficulties and ambiguities. It has consequently modernized the methods of teaching them:

"Language comparison is of great interest in a theoretical as well as an applied perspective. It reveals what is general and what is language specific and is therefore important both for the understanding of language in general and for the study of the individual languages compared". (Johansson and Hofland, quoted in Johansson's paper, 1999)

With this statement the historical background reaches its end.

\section{BILINGUAL OR MUlTilingual COMPARISON?}

Whether the aim is pedagogical or the search for language universals, it has been taken customary that the technique of CA simply means comparing TWO languages. Thus researchers compare the foreign language with the native language just to delineate points of ease and difficulty in foreign language learning. In translational CA, the source language is compared with the target language.

In a daring paper whose draft (1999) has been accessed to for the present essay through the Internet, S. Johansson, A Norwegian scholar, urges for a multilingual corpus for CA:

"If we want to gain insight into language and translation generally, and at the same time highlight the characteristics of each language, it is desirable to extend the comparison beyond language pairs".

Johansson tells that the original project that developed a bilingual corpus for CA and translation studies (the English - Norwegian Parallel Corpus) has been extended to the include translations of the English original into six languages:

$\begin{array}{lcl}\text { Swedish } & \text { Norwegian } & \text { German } \\ \text { Dutch } & \text { English } & \text { Portuguese } \\ & \text { Finnish } & \end{array}$


In justifying this extension, Johansson lists these four advantages of a multilingual CA:

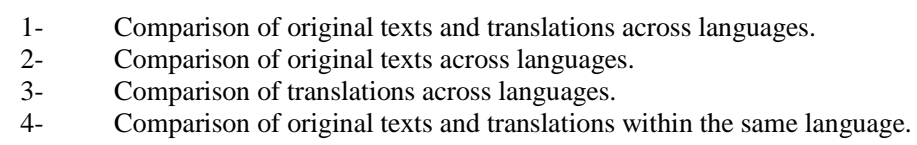

R. Salkie, however, goes further in stipulating corpora for CA, taking them as one of the reasons for its revival:

"Parallel corpora [i.e. multilingual corpora] are a valuable source of data; indeed, they have been a principal reason for the revival of contrastive linguistics that has taken place in the 1990s". (Salkie, 1999, quoted by Johansson)

As a matter of fact, the use of multilingual corpora adds more validity and accuracy to the comparison, it can also be a good place for making and testing cross-linguistic hypotheses.

It is especially important in macrolinguistic comparison.

\section{CRITERIA FOR COMPARISON}

All types of comparison require a certain degree of sameness. This level of sameness acquires more importance if we contrast things with each other rather than compare then to each other. In CA, this sameness is usually called the constant variable or the tertium comparationis (TC). For one reason or another, it is easier to agree on a TC for phonology or vocabulary than to find one for grammar:

"For phonology the IPA chart and vowel diagram seemed strong candidates, while for lexis the (probably universal) set of semantic components seemed useful. But we have so far failed to identify any such obvious TC for grammatical CA. Over the years three candidates have been proposed: surface structure, deep structure, and translation equivalence". (James, 1980,p. 169). (Let us use from now on the new terms: S-structure for surface structure and D-structure for deep structure)

\section{A. S-Structure}

The S-structure can be chosen as a TC only if there is a grammatical category that is overtly common in both languages. Being based on the structural lines that exclude meaning from the scope of their study, it recognizes two dimensions only: form and distribution.

The main advantage of choosing it as $\mathrm{TC}$ is that it is the structure which foreign language learners are confronted with.

The disadvantage is that it does not tell us about the structural formation of a sentence. It is sometimes misleading as it superficially deals with sentential and differences. In comparing the English and Arabic sentences:

This is a book

/hatha kitaabun/

one should not say that indefiniteness is marked in English but not in Arabic simply because Arabic lacks an article like 'a' before the indefinite noun. Al-tanween at the end of that noun is the substitute.

\section{B. D-Structure}

The chief advantage of choosing the D-structure is that it is for many people language independent. Hence, it can be used as a common denominator for two superficially different sentences in two different languages.

Ahmed is easy to please

/minel sahli 'irdha:' 'hmed/ من السهل إرضاء أحمد

So, if we agree with the people who believe in the universality of the D-structure, then we may assume that these two sentences come from one D-structure, which is mapped unto two S-structures via transformations. The two justifications for this assumption are that the two sentences have the same meaning and that transformational rules are meaning-preserving (Let us put aside for the moment the modern claim that meaning is determined in the S-structure).

Another advantage for choosing the D-structure as TC is that second language learners do intentionally or unintentionally return to D-structure by disregarding in one way or another what is transformationally added such as the auxiliary 'do' or moved such as tense realization.

A third advantage of resorting to D-structure is that one can see whether the two sentences in the compared languages do differ in their transformational steps or not and at which stage they diverge if they do.

One may cite here James's examples with a slight change in the layout:

\begin{tabular}{|l|l|l|}
\cline { 2 - 3 } \multicolumn{1}{l|}{} & English & German \\
\hline D-structure & I have apple. The apple is red & Ich habe einen Apfel. Der Apfel ist rot \\
\hline T-relative & I have an apple which is red & Ich habe einer Apfel, der rot ist \\
\hline T-deletion & I have an apple ... red & Ich habe einen Apfel ... rot \\
\hline T-shifting & I have a red apple (S-structure) & Ich habe einen rot Apfel (S-structure) \\
\hline
\end{tabular}

(James, p. 42). 
The disadvantage of choosing the D-structure in its Chomskyan concept in the standard theory (1965) is that it may ignore the communicative dimension of the sentence. The partial remedy is to add the pragmatic flavor, which Hymes, among others, added in his communicative competence.

\section{Translation Equivalence}

The first problem, which meets one in selecting translation equivalence as TC is: what is translation equivalence ? Sameness of meaning is of course not enough. James suggests that it may be defined in terms of D-structures on the ground that the D-structure "incorporates" and James here quotes Chomsky (1965), "all information relevant to the single interpretation of a particular sentence". (James, 1980, p. 178).

James then quotes and supports Krzeszowski's claim that 'equivalent constructions have identical deep structures." (Ibid)

The problem here is that all these three references: Chomsky's Aspects (1965), Krzeszowski's paper (1971) and James's book (1980) do not conform to the Modified Extended Standard Theory (1975) which assigned the responsibility of the sentential meaning determination to the S-structure.

A viable alternative is Lakoff's suggestion that we may go to selectional and co-occurrence restrictions: if two sentences in two languages are subject to the same restrictions and if they mean the same at the same time, they are translationally equivalent.

To add to the rejection of the D-structure identity in defining translation equivalence is the fact that D-structure is concerned with one type of meaning only: the ideational meaning or the experiential meaning as it has been recently called. It does not concern itself with what Halliday calls interpersonal and textual meaning. (Ibid, p. 178).

James defines them as follows:

"The interpersonal meaning of a sentence determines what kind of speech act it performs for its user: to praise, condemn, refuse, agree, and so on. The textual meaning of a sentence determines what information it contributes to the message: how it helps maintain cohesion and coherence". (Ibid)

The conclusion then is that translation equivalence is the most reliable TC, once we define it accurately.

\section{SAMPLE ANALYSIS}

Without going into the details of the content, which is beyond the realm of this paper, a swift glance at the 25 theses enables one to make the following remarks:

\section{A. Subject Matter:}

$72 \%$ syntax

$16 \%$ phonology

$8 \%$ morphology

$4 \%$ semantics

Thus the focus has been exclusively on syntax. Moreover, one may notice here that ALL these 25 theses have adopted the same aim-the pedagogical aim of CA: they have been written simply to predict the mistakes made by Arab learners of English by locating areas of differences between the two languages. The authenticity of this premise has been taken for granted and none of them expressed the doubts exposed above concerning this pedagogical assumption. The mere fact that none of these theses thought of choosing the other aim, which is gaining more and more importance nowadays, simply implies that our Iraqi universities hardly allot any space in their curricula for the search of linguistic universals, nor for directing CA for checking these universals arrived at these days. It is a pity that this new perspective has not evolved in our Iraqi universities yet.

Besides, this focus on syntax justifies urging new researchers to pay more attention to other areas like contrastive macrolinguistics and contrastive lexicography.

In macrolinguistics, a suitable example is to see how text analysis may be carried out in Arabic and English. One can see what lexical and grammatical devices may be valid in this analysis in both languages.

One can also check to what extent it is possible to apply to this analysis the Functional Sentence Perspective approach which was developed some fifty years ago by well-known Czech linguists like Mathesius and Fibras and which divides sentence information into 'given' and 'new' items or into 'theme' and 'rheme' in terms of this approach.

We may also realize how discourse analysis can be carried out in Arabic and English by comparing the various sentential functions in both languages: statements, commands, and questions, . . . by checking what discourse markers and rhetorical devices abound in each language.

Conversation can be another suitable area as well: what are the major components of conversation in Arabic and English? What are the familiar topics for phatic communion in them?

The familiar scale of units of discourse in English is as follows:

Turn - - - - - Move - - - - - exchange - - - - - conversation

One may apply this scale to Arabic and see how it works. 
The other absent area is lexicography. It is possible here to see how Sapir-Whorf Hypothesis of linguistic determinism may work on Arabic and English, and what word fields and semantic components are similar in the two languages.

\section{B. Models of Comparison}

With respect to syntax, the two major models of comparison are structural grammar and transformational grammar. The majority of these theses adopted the structural model. The suggestion here is that more attention may be paid to the second model as it has its own advantages over the first one. Transformational grammar supplies the contranstivist through its Universal Base Hypothesis with a universal base common to all languages and with the formal universals through language differences are ideally explained:

"Certain differences between English and German can only be observed if a transformational grammar is adopted as theoretical framework for one's statements" (Koning, quoted by James, 1980,p. 42).

Another advantage is that this model provides the constructivist with a scale of measuring differences:

". . . The T-GG approach provides the contrastive analyst with some kind of measure of degree of difference between compared constructions in L1 and L2". (Ibid ,p. 45).

\section{Number of Languages}

It is quite normal to expect all the theses of the present sample to execute a two-language analysis. The recommendation is that some attempts from now on may follow the Norwegian example by comparing three or more languages or translation texts at the same time.

\section{TC}

None of the 25 theses tried to establish a TC for the comparison. It seems that a researchers in such a case takes the presence of a TC in the comparison for granted. Subject - Verb Inversion: what is a subject in English? What is a subject in Arabic? Does it have the same distribution in both languages? In statements in Arabic a subject may appear before the verb or after it. In English it is a different case. So, where is the constant variable? It should be established right before running the comparison.

As stated above, translation equivalence is perhaps the best TC for syntactic comparison.

\section{E. Form of Arabic Language}

Unlike the English language that appears in this sample in two forms only (English in six theses) and (Standard English in 19 theses), Arabic appears in 5 shapes:

- Arabic in 6 theses.

- Standard Arabic in 11 theses.

- Modern Standard Arabic in 4 theses.

- Baghdadi Arabic in 3 theses.

- Iraqi Arabic in 1 thesis.

Since the other language is Standard English, the normal course of things is to compare it with Standard Arabic.

What draws one's attention is that 4 researchers compared Standard English with modern Standard Arabic, without realizing that they are virtually excluding in this way Kuranic Arabic and the great treasures of Arabic heritage.

The fact is that Modern Standard Arabic is a mere illusion which does not stand any reality and that Standard Arabic is one and the same during the days of Prophet Mohammed and nowadays.

The other remark goes to Baghdadi or Iraqi Arabic. These two forms of Arabic may be compared with dialectal English only, as the choice of the linguistic form will affect the formality level of the subject matter and the degree of commitment to grammatical and stylistic requirements.

\section{F. Updating the Field}

Arabic - English constructivists ought to take into consideration the new modes of comparison in the last decade or so.

They may focus on applying some principles and parameters to Arabic to see to what extent they fit and to what extent they do not.

This focus entails selecting suitable topics and techniques that cope with what is going on nowadays. Here are few examples:

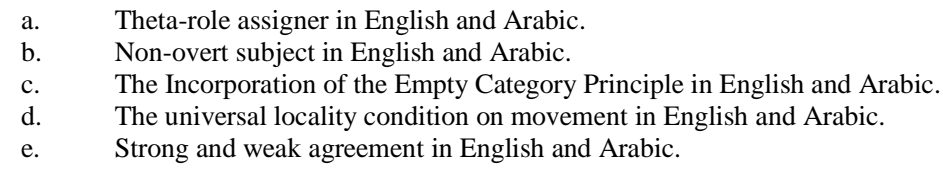

To sum up, the present paper has surveyed the current situation of Arabic-English contrastive analysis on a general historical background. 
It is hoped that it has critically viewed the details of this field and that it has authentically attempted to participate in updating it.

THE THESES SAMPLE

\begin{tabular}{|c|c|c|c|c|}
\hline No. & Researcher & Title & University & Year \\
\hline $1-$ & A.K.R. & $\begin{array}{l}\text { A Contrastive Study of Standard English \& Baghdadi Arabic Assimilation } \\
\text { Pattterns of Consonants }\end{array}$ & Baghdad & 1976 \\
\hline $2-$ & A.S.T. & A Contrastive Study of English \& Baghdadi Arabic Passivization & Baghdad & 1976 \\
\hline $3-$ & S.A.R.K. & $\begin{array}{l}\text { A Contrastive Study of Standard English and Baghdadi Arabic Word Stress } \\
\text { Patterns }\end{array}$ & Baghdad & 1977 \\
\hline $4-$ & A.M.H.J. & $\begin{array}{l}\text { A Contrastive Analysis of the Article System in Standard English \& Modern } \\
\text { Standard Arabic }\end{array}$ & Baghdad & 1978 \\
\hline $5-$ & M.M.S.A. & $\begin{array}{l}\text { WH Question Structures in Standard English \& Their Counterparts in } \\
\text { Standard Arabic }\end{array}$ & Baghdad & 1979 \\
\hline 6- & T.A.R.I. & $\begin{array}{l}\text { A Contrastive Study of Relativization in Contemporary English \& Modern } \\
\text { Standard Arabic }\end{array}$ & Mosul & 1981 \\
\hline $7-$ & H.M.F. & Futurity in Standard English \& Standard Arabic & Baghdad & 1983 \\
\hline $8-$ & Z.A.A. & Comparison in Standard English \& Standard Arabic & Baghdad & 1983 \\
\hline No. & Researcher & Title & University & Year \\
\hline 9- & A.K.J. & Time Adverbials in Standard English \& Standard Arabic & Baghdad & 1984 \\
\hline $10-$ & A.M.H. & Realization of Request in English \& Arabic & Basrah & 1984 \\
\hline $11-$ & J.H.M. & $\begin{array}{l}\text { A Contrastive Study of the Semantically-Based Linguistic Reference in } \\
\text { English \& Arabic }\end{array}$ & Mosul & 1984 \\
\hline $12-$ & S.A.H. & $\begin{array}{l}\text { A Contrastive Study of Manner Adverbials in Standard English \& Standard } \\
\text { Arabic }\end{array}$ & Baghdad & 1984 \\
\hline $13-$ & S.Z.Y. & Description \& Contrastive Analysis of Ellipsis in Standard English \& Arabic & Basrah & 1984 \\
\hline $14-$ & W.Y.M. & $\begin{array}{l}\text { A Contrastive Study of Subordination in Standard English \& Modern } \\
\text { Standard Arabic }\end{array}$ & Mosul & 1984 \\
\hline $15-$ & E.S.D. & Locatives in Both English \& Arabic & Baghdad & 1986 \\
\hline $16-$ & K.N.O. & A Contrastive Study of Topicalization in English \& Arabic & Baghdad & 1986 \\
\hline $17-$ & M.M.S. & A Study of Stress Patterns in English \& Modern Standard Arabic & Mosul & 1986 \\
\hline
\end{tabular}

\begin{tabular}{|l|l|l|l|l|}
\hline No. & Researcher & Title & University & Year \\
\hline \hline $18-$ & N.S.M. & $\begin{array}{l}\text { A Contrastive Study of Indirect Object Movement in Standard English \& } \\
\text { Standard Arabic }\end{array}$ & Baghdad \\
\hline $19-$ & I.H.M. & A Grammatical Study of Vocatives in English \& Arabic & Mosul \\
\hline $20-$ & S.S.A.B. & $\begin{array}{l}\text { A Contrastive Study of Standard English \& Standard Arabic Syllable } \\
\text { Structure }\end{array}$ & Baghdad & 1987 \\
\hline $21-$ & R.M.H.M. & Noun Phrase Structure \& Functions in Standard English \& Standard Arabic & Al-Mustansiriya & 1988 \\
\hline $22-$ & M.A.A.S. & $\begin{array}{l}\text { A Contrastive Study of Consonant Clusters in Standard English \& Iraqi } \\
\text { Arabic }\end{array}$ & Basrah \\
\hline $23-$ & Y.M.H. & $\begin{array}{l}\text { Subjective-Verb Inversion: A Contrastive Study of One Aspect of Word } \\
\text { Order in Standard English \& Standard Arabic }\end{array}$ & Baghdad \\
\hline $24-$ & K.M.A.A. & $\begin{array}{l}\text { Prepositions \& Prepositional Collocations: An English - Arabic Contrastive } \\
\text { Study }\end{array}$ & Al-Mustansiriya & 1995 \\
\hline $25-$ & S.F.T. & Lexical Similarity between Standard Arabic \& Standard English & Al-Mustansiriya & 1996 \\
\hline
\end{tabular}

CLASSIFICATION OF THE SAMPLE ACCORDING TO SUBJECT MATTER
\begin{tabular}{|l|l|l|l|l|}
\hline Syntax & Phonology & Morphology & Semantics & Total \\
\hline $\begin{array}{l}2,4,5,6,7,8,9,10,12,13, \\
14,15,16,1819,21,23,24\end{array}$ & $1,3,17,22$ & 20,25 & 11 & \\
\hline 18 & 4 & 2 & 1 & $=(\mathbf{2 5})$ \\
\hline
\end{tabular}

CLASSIFICATION OF THE SAMPLE ACCORDING THE FORM OF THE LANGUAGE

\begin{tabular}{|c|c|c|c|c|c|}
\hline $\begin{array}{l}\text { Standard English vs. } \\
\text { Standard Arabic }\end{array}$ & $\begin{array}{l}\text { Standard English vs. } \\
\text { Modern Standard Arabic }\end{array}$ & $\begin{array}{l}\text { English vs. } \\
\text { Arabic }\end{array}$ & $\begin{array}{l}\text { Standard English vs. } \\
\text { Baghdadi Arabic }\end{array}$ & $\begin{array}{l}\text { Standard } \text { English } \\
\text { vs. Iraqi Arabic }\end{array}$ & Total \\
\hline $\begin{array}{l}5,7,8,9,12,13,18, \\
20,21,23,25\end{array}$ & $4,6,14,17$ & $\begin{array}{l}10,11,15, \\
16,19,24\end{array}$ & $1,2,3$ & 22 & \\
\hline 11 & 4 & 6 & 3 & 1 & $=(25)$ \\
\hline
\end{tabular}

\section{REFERENCES}

[1] Aitchison, J. (1987). Linguistics. Kent: Hodder and Stoughton.

[2] Ellis, R. (1985). Understanding Second language Acquisition. Oxford: OUP.

[3] Fries, C. (1945). Teaching and Learning English as a Foreign Language. Ann Arbor: University of Michigan Press. 
[4] Haegeman, L. and J. Gue'ron. (1999). English Grammar. Oxford: Blackwell Publishers Ltd.

[5] James, C. (1980). Contrastive Analysis. Essex: Longman Group Ltd.

[6] Johansson, S. (1999). Towards a Multilingual Corpus for Contrastive Analysis and translation Studies. http://www.hf.uio.no/germany/sprik/ accessed 29/2/2008.

[7] Lyons, J (1968). Introduction to Theoretical Linguistics. Cambridge: CUP.

[8] Ouhalla, J. (1999). Introducing Transformational Grammar. London: Arnold.

[9] Saussure, F. (1959). Course in General linguistics. New York: McGraw Hill.

[10] Simpson, J (1979). A First Course in Linguistics. Edinburgh: Edinburgh University Press.

[11] Skinner, B. (1957). Verbal Behavior. New York: Appleton Century Crofts.

[12] Yule, G. (1988). The Study of Language. Cambridge: CUP.
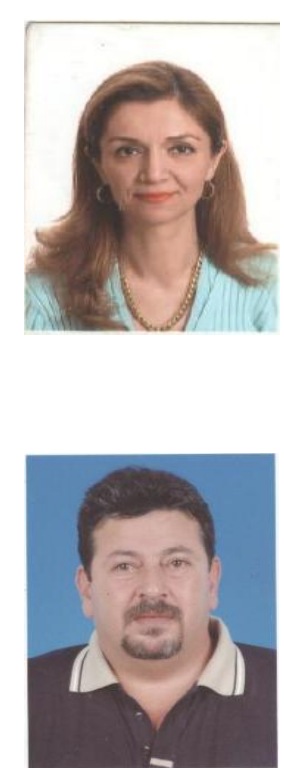

May F. Al-Shaikhli was born in Baghdad, Iraq 1970. She got her Ph. D degree in Linguistics and Translation from Mousel University and her MA, and BA degrees in Translation from AL Mostanseriya University in Baghdad Iraq. Her major field is pure Translation with all its branches such as Literary, Scientific, Legal, and Mass Media, consecutive and simultaneous ones.

She is currently occupying an Assistant Professor position in Translation in the College of Arts and Humanities at AL-Isra University in Amman-Jordan. From 2005-2007 she worked, also, as an Assistant Professor in Translation in the College of Arts and Humanities at Middle East University (MEU) for Graduate Studies Amman-Jordan. She worked an Instructor at AL-Turath college and AL-Mustanseriya University and a Translator in the Ministry of Education in Baghdad-Iraq.

Ibrahim Abdel-Latif Shalabi was born in Jordan, 1961. He got his Ph.D. in American Literature from the Vidyapeeth University, Udaipur, Rajasthan, India, 1994. His Bachelor of Arts in English Literature is from the University of Rajasthan, India, 1986, while his Master of Arts in English Literature is from Mohan Lal Sukhadia University, Udaipur (INDIA) 1989.

$\mathrm{He}$ is currently the Chairman of the Department of English at Isra University, Amman, Jordan. He was also the Chairman of the Department of English at the same University from 2006-2009. Moreover, he worked as an Assistant Professor at the Department of English, Isra University, Amman, Jordan from 2003 to Present. $\mathrm{He}$ is a member at the Board of the Faculty of Arts and was an External Examiner in a committee for the public defense of an MA thesis. Some of his Publications are: COLERIDGE,S CRITICISM and MAJOR THEMES IN RENAISSANCE UTOPIAS. 